
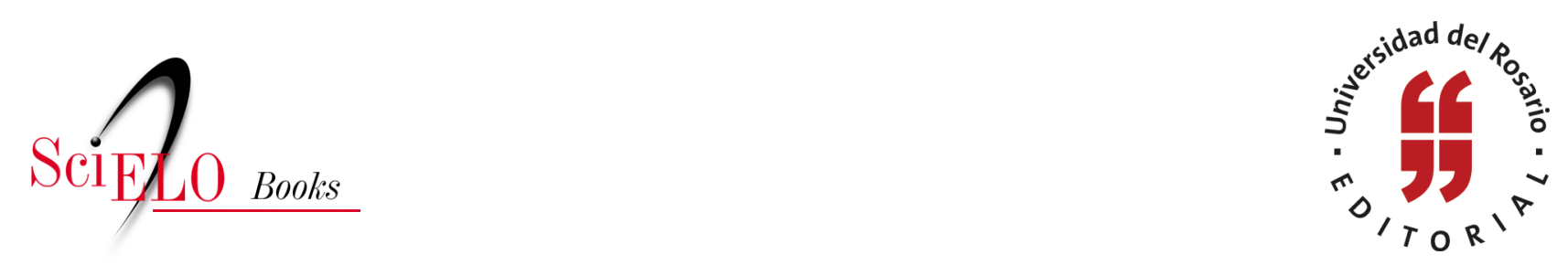

\title{
3. El daño desde la teoria de la responsabilidad ambiental
}

\author{
Gustavo Adolfo Ortega Guerrero \\ Tito Simón Ávila Suárez
}

\section{SciELO Books / SciELO Livros / SciELO Libros}

ORTEGA GUERRERO, G.A., and ÁVILA SUÁREZ, T.S. EI daño desde la teoria de la responsabilidad ambiental. In: AMPARO RODRÍGUEZ, G., and VARGAS CHAVES, I., ed. Perspectivas de responsabilidad por daños ambientales en Colombia [online]. Bogotá: Editorial Universidad del Rosario, 2015, pp. 93125. Textos de Jurisprudencia collection. ISBN: 978-958-738-644-8.

https://doi.org/10.7476/9789587386448.0004.

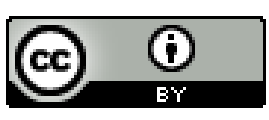

All the contents of this work, except where otherwise noted, is licensed under a Creative Commons Attribution 4.0 $\underline{\text { International license. }}$

Todo o conteúdo deste trabalho, exceto quando houver ressalva, é publicado sob a licença Creative Commons Atribição 4.0.

Todo el contenido de esta obra, excepto donde se indique lo contrario, está bajo licencia de la licencia $\underline{\text { Creative }}$ Commons Reconocimento 4.0 . 


\title{
3. El daño desde la teoría de la responsabilidad ambiental
}

\author{
Gustavo Adolfo Ortega Guerrero* \\ Tito Simón Ávila Suárez**
}

\section{Introducción}

El concepto de 'daño ambiental' ha venido experimentando una transformación tanto normativa como jurisprudencial y dogmática, que, aunque continúa involucrando aspectos importantes, puede ser considerada como la superación de la visión primigenia del derecho civil privatista hacia la consolidación del debate que empieza a incluir una visión integral que da cuenta de una serie de valores y principios indispensables para tratar los efectos tanto ecológicos como sociales que están llamados a ser valorados como consecuencia de la generación del daño. Esta perspectiva, precisamente, ha permitido replantear la noción que debe ser adoptada desde la teoría de la justicia y la responsabilidad ambiental a fin de solucionar aquellos problemas vinculados a la contaminación, el daño ambiental y los pasivos ambientales, bajo el entendido de que quien origina el daño ambiental mantiene una responsabilidad que no solo

* Abogado de la Universidad Nacional de Colombia; magíster en Ambiente y Desarrollo de la Universidad Nacional de Colombia y el Instituto de Estudios Ambientales (IDEA); estudiante del Doctorado en Derecho de la Universidad Nacional de Colombia. Profesor ocasional de la Universidad Nacional de Colombia; coordinador del Grupo de Investigación en Derechos Colectivos y Ambientales (Gidca) de la Universidad Nacional de Colombia y docente investigador de la Universidad Manuela Beltrán. Correos electrónicos: gaog30@hotmail.com, gaortegag@unal.edu.co

** Abogado de la Universidad Libre de Colombia; especialista en Derecho Administrativo; especialista en Gerencia de Recursos Naturales; especialista en Derecho Ambiental; magíster en Biociencias y Derecho de la Universidad Nacional de Colombia. Profesor de las especializaciones en Derecho Ambiental de la Universidad del Rosario y Gestión Ambiental de la Escuela de Posgrados de la Policía Nacional (Espol) y la Universidad de La Sabana, y de la Maestría en Gestión de la Empresa Minero-Energética de la Escuela de Administración de Negocios (EAN).Correo electrónico: titosimonavilasuarez@gmail.com 
recae en la identificación de una conducta, sino adicionalmente en la exigencia de una responsabilidad ampliada que le exige restaurar in natura y compensar por los daños ambientales, tanto ecológicos como sociales, cuando se observa que estos han sido trasgredidos. Los diferentes avances jurisprudenciales y dogmáticos, incluyendo la diferenciación del daño ambiental puro e impuro, son solo una muestra de la necesidad dinámica de establecer elementos tanto sustanciales como instrumentales que permitan encausar la teoría sobre el daño ambiental dentro de los criterios de la justicia ambiental, especialmente vinculados a las actividades de uso, aprovechamiento, explotación, extracción, consumo e intercambio de los recursos naturales.

Por lo tanto, el presente trabajo busca identificar y abordar esta transformación respecto al daño ambiental en sus tres principales dimensiones: i) en una revisión del derecho en las disposiciones del derecho ambiental internacional, en las disposiciones constitucionales en Colombia y en los aspectos normativos de la legislación que desarrollan los instrumentos de regulación directa, como el procedimiento sancionatorio ambiental; ii) en la conceptualización jurisprudencial del daño ambiental tanto de la jurisprudencia internacional comparada como de los avances de la jurisprudencia nacional; $y$, finalmente, iii) frente a las cuestiones dogmáticas del daño ambiental y otros conceptos importantes, como la contaminación y los impactos y daños ambientales, por ejemplo, los pasivos ambientales. ${ }^{1}$

\subsection{Avances desde la jurisprudencia internacional y nacional sobre el daño ambiental y la teoría de la responsabilidad ambiental} Para empezar, debe considerarse que el tema del daño ambiental ha transcendido con los avances del derecho ambiental a partir de las conceptualizaciones que marcan la evolución de las medidas sobre la protección del ambiente, y que inician con el derecho ambiental internacional (DAI) desarrollado a partir de las grandes declaraciones ambientales, esto es, la Declaración de Estocolmo sobre Ambiente Humano de 1972, la Declaración de Río de Janeiro de 1992 y la Declaración de Johannesburgo sobre Desarrollo Sostenible de 2002. Aunque, si bien se aclaran las disposiciones del derecho suave (soft law) o no vinculante, como la primera y la última declaración, y las disposiciones de 'derecho fuerte'

\footnotetext{
${ }^{1}$ El presente trabajo se vincula al desarrollo de Ávila (2014), y fue elaborado por los autores a partir de la investigación sobre daño ambiental ante la Autoridad Nacional de Licencias Ambientales (ANLA).
} 
vinculante (hard law), que, para el caso del ordenamiento jurídico colombiano, se remiten a la Declaración de Río de Janeiro de 1992, las cuales fueron incorporadas por el artículo $1^{\circ}$ de la Ley 99 de 1993 como parte de los elementos que deben aplicarse a la política ambiental nacional (onU, 1972, 1992, 2002; CRC, 1993).

En esta medida, se identifican dentro del sistema de principios desarrollados internacionalmente las disposiciones referidas al tema del daño ambiental. Por ejemplo, la Declaración de Estocolmo en su principio 22 establece que "los Estados deben cooperar para continuar desarrollando el derecho internacional en lo que se refiere a la responsabilidad y a la indemnización a las víctimas de la contaminación y otros daños ambientales que las actividades realizadas dentro de la jurisdicción o bajo el control de tales Estados causen en zonas situadas fuera de su jurisdicción", y en el principio 23 indica que "toda persona, de conformidad con la legislación nacional, tendrá la oportunidad de participar, individual o colectivamente, en el proceso de preparación de las decisiones que conciernen directamente a su medio ambiente y, cuando éste haya sido objeto de daño o deterioro, podrá ejercer los recursos necesarios para obtener una indemnización" (onu, 1972).

Posteriormente, en la Declaración de Río de Janeiro de 1992, se instituyó dentro de su principio 2 el 'principio de soberanía' de los Estados sobre sus recursos, sobre su política ambiental y sobre sus actividades, siempre que no afecten a otros Estados, idea que se desarrolló teóricamente bajo la denominación de la 'regla del no daño' o responsabilidad por daños ocasionados a otros países (onu, 1992; Tol y Verheyen, 2004). También, en el principio 10, se reconoció la necesidad de establecer garantías por parte de los Estados, quienes a partir de ese momento debían conceder "acceso efectivo a los procedimientos judiciales y administrativos, entre éstos el resarcimiento de daños y los recursos pertinentes". En el principio 13, se menciona el deber de los Estados para "[...] desarrollar la legislación nacional relativa a la responsabilidad y la indemnización respecto de las víctimas de la contaminación y otros daños ambientales", así como para impulsar la creación de nuevas leyes internacionales en materia de responsabilidad e indemnización "[...] por los efectos adversos de los daños ambientales causados por las actividades realizadas dentro de su jurisdicción $[\ldots]$ ”.

Más tarde, con la aprobación de la Constitución Política de 1991, se determinó como parte de las obligaciones a cargo del Estado, dentro del 
artículo 80, la planificación sobre el "[...] manejo y aprovechamiento de los recursos naturales, para garantizar su desarrollo sostenible, su conservación, restauración o sustitución, pero adicionalmente, el deber de '[...] prevenir y controlar los factores de deterioro ambiental, imponer las sanciones legales y exigir la reparación de los daños causados". Igualmente, el artículo 88 señala que la ley “[...] definirá los casos de responsabilidad civil objetiva por el daño inferido a los derechos e intereses colectivos [...]” (ANC, 1991).

Y de forma más reciente, dentro de los desarrollos de la legislación en Colombia en materia de responsabilidad frente al daño ambiental, en la Ley 1333 de 2009, que desarrolló las disposiciones sobre el procedimiento sancionatorio ambiental, se incluyó dentro de las infracciones objeto de investigación y sanción "la comisión de un daño al medio ambiente, con las mismas condiciones que para configurar la responsabilidad civil extracontractual" (el daño, el hecho generador con culpa o dolo y el nexo causal). Al respecto, en el procedimiento sancionatorio ambiental se diferencia entre la 'sanción' propiamente dicha y la 'responsabilidad' "que para terceros pueda generar el hecho en materia civil” (artículo 5\%), aclarándose además frente a las medidas compensatorias que "la imposición de una sanción no exime al infractor del cumplimiento de las medidas que la autoridad ambiental competente estime pertinentes establecer para compensar y restaurar el daño o el impacto causado con la infracción" (artículo 31). Un aspecto adicional que puede encontrarse en la Ley 1333 de 2009 ha sido la aplicación del principio de prevención que se desarrolla a través de la posibilidad de decretar medidas preventivas (artículo 36) a fin de evitar la generación del daño o peligro sobre el ambiente (previniendo además la agravación o generación de daños adicionales) (CRC, 2009).

\subsubsection{Jurisprudencia internacional comparada en materia del daño ambiental y responsabilidad ambiental}

La conceptualización y fundamentación jurídica del daño ambiental, como la teoría de la responsabilidad ambiental, se han visto marcadas en la actualidad por los avances y la evolución de desarrollos del derecho ambiental, que antes estaban reducidos de manera exclusiva a las teorías puras de la responsabilidad civil y/o administrativa. Es así que se han generado nuevas tendencias para producir un cambio de perspectivas encaminadas a garantizar el conjunto de valores sociales reconocidos en los mandatos constitucionales y en los ordenamientos jurídicos contemporáneos en materia de protección ambiental. 
De arreglo con este argumento, han existido notables progresos de la conceptualización jurisprudencial del daño ambiental, superando a su vez las primeras fases de la responsabilidad civil extracontractual, que, si bien aporta elementos muy importantes, pueden resultar insuficientes para abordar el tema desde una perspectiva de valoración y reparación integral del daño. En esta medida, se establece un análisis jurisprudencial en contexto, con alcances cada vez más inclusivos y garantistas, partiendo de planteamientos sobre las problemáticas ambientales desde la perspectiva ecológica asociada a los bienes afectados, pero que cada vez más van integrando aspectos sociales y elementos de protección y reparación más allá de las sanciones e indemnizaciones monetarias, lo que, en otras palabras, implica una visión integral a los problemas de valoración ambiental del daño.

Comenzando con la jurisprudencia de la Corte Internacional de Justicia (CIJ), si bien no se ha manifestado de fondo sobre aspectos del DAI, sí se han suscitado algunos casos relativos al daño ambiental transfronterizo (Uribe Vargas y Cárdenas Castañeda, 2010). Así, por ejemplo, la Asamblea General de la onu requirió Opinión Consultiva de la cij en 1996 respecto a la legalidad del Tratado de Utilización de las Armas Nucleares (The legality of the Threat or Use of Nuclear Weapons), en la cual se sostuvo la necesidad de reconocer que el ambiente está constante amenazado e, igualmente, que este "no es una abstracción", sino el espacio "donde viven los seres humanos y del cual depende la calidad de vida y salud, así como el bienestar de las generaciones del futuro. En consecuencia deja claro en cuanto la responsabilidad de los Estados de actuar dentro de los límites sin dañar el ambiente o los territorios" (cIJ, 1996).

En otro caso, como el de Gabcikovo-Nagymaros (1997), concerniente a la construcción y funcionamiento del sistema de exclusas Gabcikovo-Nagymaros entre la República Popular de Hungría y la entonces República Socialista de Checoslovaquia, quienes pretendían utilizar los recursos naturales de la sección Bratislava-Budapest del río Danubio respecto a proyectos hidráulicos y energía, la Corte señaló que en los últimos tiempos la protección del 'equilibrio ecológico’ debe ser considerada como un interés esencial de los Estados, en donde se impone la prevención en virtud del carácter "irreversible de los daños causados al ambiente y de los límites inherentes a los mecanismos de reparación de este tipo de perjuicios" (cIJ, 1997).

Dando paso a los desarrollos más importantes a nivel de jurisprudencia internacional, se cita el caso Zander vs. Suecia, resuelto por la Corte Europea 
de Derechos Humanos (CEDH) en 1993, que vinculará la conceptualización del 'daño ambiental' con la teoría de la responsabilidad ambiental y las 'medidas de compensación'. Con base en la demanda, la Corte analiza la contaminación por vertimientos domésticos e industriales que fueron permitidos por los gobiernos nacional y regional de Suecia mediante la expedición de licencia administrativa, en la cual se comprobaría, a través de su seguimiento, la existencia de altos contenidos de cianuro en las fuentes de agua que abastecían a una comunidad local. La argumentación de la CEDH se remite de manera directa al desconocimiento de 'derechos civiles' de los demandantes, por la no aplicación de medidas de prevención suficientes frente a daños causados por actividades peligrosas para el ambiente, en especial aquellas que por virtud de los usos del suelo conllevaron inter alia (entre otras cosas) a la contaminación del agua. Y concluye la Corte que, debido al desconocimiento de la legislación interna de Suecia, específicamente de la Ley 1969 sobre las medidas cautelares frente a la contaminación, y de la Ley de Daño Ambiental de 1986 en relación con la indemnización del daño causado, al no haber sido objeto de control judicial ni los hechos de la empresa ni los actos administrativos expedidos por la Junta de Licencias, se declara la violación del artículo $6^{\circ}$ del Convenio Europeo de Derechos Humanos en materia de garantías judiciales, y se reconoce a favor de las víctimas una indemnización por los 'daños morales' ocasionados, ya que, a pesar de las medidas preventivas, como el abastecimiento de agua no contaminada para los afectados, estos vivían en una constante preocupación frente a la posibilidad de un eventual envenenamiento (CEDH, 1993).

Acorde con lo anterior, puede verse cómo en la evolución de la responsabilidad frente al daño ambiental la jurisprudencia internacional ha incluido una serie de elementos sociales que sobrepasan la apreciación del simple daño ecológico, pues, como se deriva de la ratio decidendi (o razón fundamental de la decisión) del caso Zander vs. Suecia, las medidas de compensación se centran además en los valores y principios sociales que pudieron verse fragmentados, por ejemplo, la 'confianza legítima' de la sociedad y las comunidades frente a las medidas del Estado.

En idéntico sentido, otras sentencias de la CEDH sobre la protección de derechos desconocidos, que han incluido en sus decisiones medidas no circunscritas exclusivamente al reconocimiento del pago monetario frente al daño ambiental ocasionado. Así, por ejemplo, en el caso Fadeyeva vs. Rusia (2005), la Corte analiza el caso de contaminación por las emisiones procedentes de 
una fábrica de acero que afectaba el lugar de residencia de los demandantes. $\mathrm{Al}$ respecto, se menciona la situación en la que, a pesar de haberse establecido un perímetro de control ambiental en la zona de influencia por parte de las autoridades, los demandantes, al igual que miles de personas, fueron alojados en apartamentos dentro de dicho perímetro. En consecuencia, la CEDH advierte que, pese a las decisiones judiciales internas que obligaban al gobierno a reubicar a las poblaciones afectadas, esto nunca se llevó a cabo, y, por lo tanto, se desconocieron los derechos a la vida privada y a la familia, lo que involucró serios problemas, como la afección psicológica y cierto grado de sufrimiento físico ante la exposición a la contaminación, hecho que, además de requerir indemnización en términos monetarios, obliga al gobierno a cumplir medidas futuras para "el reasentamiento de la demandante en una zona ecológicamente equilibrada" $y$ otro tipo de soluciones adicionales que deben ser adoptadas para resolver la situación particular de la demandante en cuanto a la reparación del daño (CEDH, 2005a).

Otro caso que refleja el tema del daño ambiental es Giacomelli vs. Italia (2006), en el cual la CEDH reconoce la violación al artículo $8^{\circ}$ del Convenio Europeo de Derechos Humanos por afectación a la vida privada por contaminación de una planta de tratamiento de residuos, que incluye contaminación por 'residuos peligrosos' y remediación a través de productos químicos, los cuales generaron afectaciones durante años al demandante (CEDH, 2006).

También, se encuentran pronunciamientos de la CEDH en otras instancias sobre las garantías de derechos constitucionales y derechos fundamentales, que tienden a ser desconocidas por los sistemas jurídicos de los países o que dejan de ser aplicadas por los gobiernos nacionales a pesar de la existencia de decisiones judiciales nacionales, por ejemplo, en la garantía del reconocimiento a los derechos a la vida, a un ambiente sano, a la evaluación de impactos adversos sobre el ambiente, y que ocasionan daños a los ecosistemas locales y la salud humana, como en las sentencias de los casos López Ostra vs. España (1994), Taskin y otros vs. Turquía (2004) y Okyay y otros vs. Turquía (2005) (CEDH, $1994,2004,2005 b) .^{2}$

\footnotetext{
${ }^{2}$ La jurisprudencia citada corresponde a casos de contaminación proveniente de actividades industriales por empresas de cuero, contaminación por cianuro de proyectos mineros de explotación de oro y operación de centrales termoeléctricas en materia de contaminación del aire y cenizas.
} 
De otro lado, bajo la perspectiva del derecho comercial internacional, se cita la sentencia del Tribunal Internacional de Arbitramento ad hoc en relación al laudo Trail Smelter Case (contaminación de hornos de fundición), que resolvió el litigio Estado Unidos vs. Canadá en materia de daños por contaminación transfronteriza, reconociendo el problema ambiental generado por las plantas fundidoras de azufre ubicadas en Canadá sobre los campos y las poblaciones del Estado de Washington en los Estados Unidos. En dicho asunto, el Tribunal concluyó que, "según los principios del derecho internacional, así como de la ley de Estados Unidos, ningún Estado tiene derecho de usar o permitir que se use el territorio de modo que se causen daños por razón de emanaciones en el territorio o hacia el territorio de otro Estado o a la propiedad o personas que allí se encuentren, cuando se trata de un hecho con consecuencias graves y el daño sea determinado a través de pruebas claras y concluyentes" (TSAT, 1941).

Sobre la sentencia al laudo Estados Unidos vs. Canadá, es importante señalar ciertas conclusiones que han sido advertidas por diferentes teóricos, entre ellas: 1) que aplica implícitamente una teoría de 'responsabilidad objetiva' por cuanto no se aportó ninguna prueba sobre la negligencia por parte de Canadá, y el Tribunal simplemente partió de su reconocimiento; y 2) que se aplicaron las medidas de responsabilidad objetiva bajo la conceptualización del sistema anglosajón del common law, en el cual se diferencia la 'responsabilidad' (responsibility) u obligación frente a los actos propios y la responsabilidad de indemnización o compensación (liability) por incumplimiento de los deberes jurídicos, en especial los de prevención (Gómez Robledo, 1992). ${ }^{3}$

Uno de los casos más recientes, paradigmáticos y representativos de la jurisprudencia comparada es el caso Salazar y otros vs. Chevron-Texaco, por la contaminación por derrame de petróleo de la empresa transnacional sobre la Amazonía en Ecuador, en la cual se destacan los argumentos acogidos por la Corte Provincial de Sucumbíos en la condena proferida contra la ChevronTexaco, que, no obstante de retomar la aplicación bajo una perspectiva civilista y privatista al examinar los elementos de la responsabilidad subjetiva que

\footnotetext{
${ }^{3}$ No obstante, como sostiene Gómez Robledo (1992), aunque puede ser uno de los primeros casos en el derecho internacional en haber definido una responsabilidad objetiva en materia del daño ambiental, algunos sostienen que había un reconocimiento tácito de responsabilidad en el mismo acuerdo arbitral por parte de Canadá.
} 
señala el artículo 1480 del Código Civil ecuatoriano (hecho, daño y nexo de causalidad), aplicó la 'responsabilidad objetiva' por la inobservancia de los "reglamentos de la industria y de otras normas administrativas" (cPs, 2012).

La Corte Nacional de Ecuador confirmó los argumentos de la Corte Provincial de Sucumbíos, reconociendo además que "existe la debida motivación respecto a la responsabilidad objetiva [...]”, pues existe la obligación de "quien causó el daño" “[...] de reparar, es decir se determina la responsabilidad y el nexo causal entre las actividades realizadas por la accionada y el daño ambiental, lo que ha conllevado a que se infrinja la ley ecuatoriana”. Luego de hacer un ejercicio de derecho comparado en materia de responsabilidad sobre el daño ambiental, concluye, con base en la Constitución Política de Ecuador, que la responsabilidad ambiental es objetiva, ya que "en materia ambiental la responsabilidad subjetiva no funciona [...] y muchos sistemas jurídicos acuden a la teoría de la responsabilidad objetiva”. Y, desde el análisis constitucional, se menciona la necesidad de que "todo daño al ambiente, además de las sanciones correspondientes, implicará también la obligación de restaurar integralmente los ecosistemas e indemnizar a las personas y comunidades afectadas" (CNE, 2013).

\subsubsection{Jurisprudencia nacional en materia de daño ambiental}

La jurisprudencia colombiana en materia de responsabilidad por daño ambiental pasa por el desarrollo realizado por la Corte Suprema de Justicia (csJ, 1976) en el caso de responsabilidad civil por contaminación al ambiente por los daños causados por la emanación de gases sulfurosos arrojados a la atmósfera (corrosión y deterioro), los cuales se depositaron en las instalaciones, maquinarias, muebles, enseres, equipos y herramientas de propiedad de Hilanderías Medellín S.A. Sin embargo, esta jurisprudencia está considerada como la definición bajo la óptica de protección a la propiedad privada, que implica reivindicación por medio de la indemnización o compensación por los daños inferidos a ella.

Así, la csj acudió a figuras del derecho civil como la responsabilidad por el abuso del derecho y la teoría del riesgo por actividades peligrosas. La Corte se refirió al tema del daño ambiental mediante la 'teoría del abuso del derecho', construida desde lo civil como: i) los derechos subjetivos que pueden y deben ejercerse sin causar daño a los demás; y ii) la excepción de los derechos que no pueden ser ejercidos sin lesionar un derecho ajeno, condensado 
en el hecho de que "nadie puede hacer uso" de sus derechos "en prejuicio de terceros", puesto que "la ley no los ha reconocido o conferido como facultad que permita atender contra el derecho ajeno, sino como medio legítimo de satisfacción de necesidades individuales o colectivas sin prejuicio de los demás". Es decir que "el que daña a otro so pretexto de usar derecho cuyo ejercicio no implique ineludiblemente daño ajeno no está ejerciéndolo sino abusando de él”. Abiertamente es la teoría sobre el 'uso de los derechos', que tienen como límite de su ejercicio el lugar donde comienzan los ajenos, lo cual, en desconocimiento de este principio, puede dar lugar a la declaratoria de responsabilidad con su respectiva indemnización. En la sentencia, se afirma que quien comete un hecho ilícito de manera culposa o dolosa que no se ha desvirtuado con la fuerza mayor o caso fortuito es "civilmente responsable por abuso del derecho" (ibíd.).

Importante señalar que la csj remite a las sentencias del 30 de noviembre de 1935, 14 de marzo y 31 de mayo de 1938, citadas en el caso Hilanderías Medellín S.A.(1976), pero también más adelante a las sentencias de los casos Acosta vs. Gases del Caribe S.A. (1999) y Ampeatum vs. Mesta Shipping Company y otros (2011), para argumentar, con respecto a lo establecido en el artículo 2356 del Código Civil, que la responsabilidad civil generada por la contaminación ambiental corresponde al régimen de las actividades peligrosas en 'virtud del riesgo o el peligro consustancial', las cuales se definen "socialmente útiles y aún necesarias pero también peligrosas", y que, pese a ser lícitas, no autorizan dañar a los demás, bastando solo con la demostración del daño y el nexo de causalidad para obtener la reparación "del perjuicio sufrido, salvo prueba de fuerza mayor, o caso fortuito o de la culpa exclusiva de la propia víctima" (csJ, 1976, 1999).

En este primer momento, la Corte establece una concepción de derechos individuales y la propiedad privada, que no describe al ambiente como un bien común y un derecho colectivo, con lo cual se concluye que, si bien representa un avance en materia de indemnización o compensación civil por el daño a la propiedad, ya sea por la 'teoría del riesgo creado o abuso del derecho', no se estima una noción de ambiente que merezca protección de forma directa, dejándolo a la suerte de la protección de la propiedad y los límites que se 
establezcan para el uso de los derechos sin dañar los de los terceros. ${ }^{4}$ Por lo tanto, pese a constituirse en uno de los primeros precedentes jurisprudenciales, en esta sentencia no se desarrolla la teoría de responsabilidad por daño o contaminación ambiental, y tampoco se tienen en cuenta los desarrollos de la Ley 23 de 1973 (CRC, 1973) y el Decreto-Ley 2811 de 1974, ${ }^{5}$ como se ha reconocido desde el punto de vista dogmático (CRC, 1974). ${ }^{6}$

Es en la sentencia del caso Ampeatum vs. Mesta Shipping Company y otros de 2011, anteriormente citada, que la csj reconoce la restricción de los anteriores pronunciamientos jurisprudenciales de la jurisdicción civil y el daño ambiental (también ecológico) como un atentado a aminoración a un bien público y colectivo que transciende los derechos individuales. Por lo tanto, la Corte señala el 'ambiente' como un bien jurídico inmaterial, unitario y autónomo, con un valor colectivo, con una dimensión social, pública, concerniente al Estado, que además constituye un 'bien y principio constitucional'

dentro del Estado social de derecho (artículos $1^{\circ}, 2^{\circ}$ y 366 superiores), un derecho fundamental por conexidad al estar ligado con la vida y la salud (artículos 11 y 49 superiores), un derecho colectivo (ser social) que compromete a la comunidad (artículo 88 superior) y un deber constitucional en cabeza de todos (artículos 8º 79, 95 y 333 superiores), [...] también tiene el carácter de servicio público [...], forma parte de los derechos colectivos [...], cuya vía judicial de protección son las acciones populares (artículo 88 superior) [...],y cuya

\footnotetext{
${ }^{4} \mathrm{La}$ csj refiere al ejercicio de actividades contaminantes en lugares alejados en los que quizá bajo un estudio técnico podría demostrarse que los ecosistemas son más frágiles o que pueden recaer en impactos sobre personas vulnerables.

${ }^{5}$ Por ejemplo, el artículo 32 del Decreto-Ley 2811 de 1974 (PRC). Igualmente, en el plano internacional se contaba como herramienta de análisis lo señalado en la Declaración de la Conferencia de la Naciones Unidas sobre el Ambiente Humano de Estocolmo de 1972, previamente citada.

${ }^{6}$ Siguiendo este análisis, Sarmiento García (2009) reconoce que, en nuestra legislación ambiental, especialmente a partir de lo señalado en el artículo 16 de la Ley 23 de 1973, se establece un régimen de responsabilidad civil bajo un esquema objetivo, que no tiene en cuenta si la conducta se desplegó con o sin culpa, como factor determinante de la responsabilidad por los daños causados al ambiente por el Estado y los particulares, aunque lo limita a los 'recursos naturales' de propiedad privada.
} 
importancia en la Constitución es de tal magnitud que implica para el Estado "unos deberes calificados de protección [...]”(ccc, 2010b). ${ }^{7}$

Y al mismo tiempo reconoce la existencia de afectaciones individuales cuando el daño es determinado o determinable, para lo cual deja de ser daño ambiental y se convierte en detrimento de los derechos individuales.

Aquí existe un cambio sustancial en la jurisprudencia de la csJ, por cuanto se cita el contenido del artículo 16 de la Ley 23 de 1973, en el cual se afirma que "el Estado será civilmente responsable por los daños ocasionados al hombre o a los recursos naturales de propiedad privada como consecuencia de acciones que generen contaminación o detrimento del medio ambiente. Los particulares lo serán por las mismas razones y por el daño o uso inadecuado de los recursos naturales de propiedad del Estado". Por esta razón, reconoce que las acciones idóneas frente a la generación del daño ambiental tienen que corresponder a la acción constitucional de la acción popular, mientras que, en el segundo caso, para obtener el pago y reconocimiento de indemnización de un conjunto plural de individuos, podrá acudirse a las acciones de grupo o a la acción ordinaria de responsabilidad civil (csJ, 2011).

La Corte Constitucional de Colombia (ccc) ha establecido a través de una serie de sentencias algunos criterios de interpretación frente al daño ambiental, en dos temas principales: i) el licenciamiento ambiental y ii) el procedimiento sancionatorio ambiental. En cuanto al licenciamiento ambiental, la ccc, en la Sentencia C-035 de 1999, se ha referido a la relación existente entre la licencia ambiental y la prevención de los daños ambientales, por ejemplo, a la necesidad de concebir la interpretación de las obligaciones surgidas del instrumento ambiental, de acuerdo con la incidencia de cada uno de los proyectos, en la medida en que los impactos pueden varían según la "naturaleza y magnitud de la respectiva obra o actividad" (ccc, 1999). En el mismo sentido, se desarrolla la argumentación en la C-746 de 2012, en la cual se vincula la licencia ambiental como instrumento para evitar y mitigar los daños ambientales (ccc, 2012a).

Así mismo, la ccc ha aclarado en la revisión de tutela de la Sentencia T-693 de 2012 (caso Unión Temporal Desarrollo Vial del Valle del Cauca y

${ }^{7} \mathrm{La}$ csj hace referencia a esta sentencia para argumentar el alcance constitucional del concepto de ambiente, referido por la ccc a las infracciones ambientales del procedimiento sancionatorio ambiental. 
Cauca vs. Ministerio de Ambiente y Desarrollo Sostenible) que, al aprobar una licencia ambiental, la autoridad ambiental competente puede hacerlo de manera general, obteniendo la facultad de condicionarla al cumplimiento de una serie de requisitos y obligaciones, con el fin de prevenir, mitigar, restablecer o compensar los 'daños causados' por la obra o proyecto (ccc, 2012b).

Ahora, en materia del procedimiento sancionatorio ambiental, la ccc en Sentencia C-293 de 2002, acudiendo al principio de precaución, estableció como criterio de interpretación que una autoridad ambiental puede proceder "a la suspensión de la obra o actividad que desarrolla el particular, mediante el acto administrativo motivado, si de tal actividad se deriva daño o peligro para los recursos naturales o la salud humana, así no exista la certeza científica absoluta", pues las consecuencias "del riesgo consiste [sic] en que el deterioro ambiental debe ser neutralizado desde sus propios orígenes y sin retardar la actuación hasta el momento mismo en que los efectos negativos se produzcan o generen mayor daño" (ccc, 1999).

Sobre el procedimiento sancionatorio ambiental, la ccc ha efectuado varios pronunciamientos en relación con la constitucionalidad de la Ley 1333 de 2009. Comenzando con la Sentencia C-401 de 2010, la Corte se refiere a la función sancionatoria y medidas preventivas del artículo $4^{\circ}$ y a la diferencia entre la sanción (artículo 40 ibíd.) y el cumplimiento de las medidas de compensación y restauración de 'daño' o el 'impacto' cuando la autoridad ambiental competente estime necesario (artículo 31 ibíd.) (ccc, 2010a).

En la Sentencia C-703 de 2010, la ccc se refiere a otros elementos de la interpretación de la Ley 1333 de 2009 en materia de procedimiento sancionatorio ambiental y de manera directa a las medidas que deben adoptar las autoridades ambientales al respecto:

La afectación, el daño, el riesgo o el peligro que enfrenta el medio ambiente constituyen el punto de partida de la formulación de los principios que guían el derecho ambiental y que persiguen, como propósito último, dotar a las respectivas autoridades de instrumentos para actuar ante esas situaciones que comprometen gravemente el ambiente y también los derechos con él relacionados. Tratándose de daños o de riesgos se afirma que en algunos casos es posible conocer las consecuencias que tendrá sobre el ambiente el desarrollo de determinado proyecto, obra o actividad, de modo que la autoridad 
competente puede adoptar decisiones antes de que el riesgo o el daño se produzcan, con la finalidad de reducir sus repercusiones o de evitarlas y cuando tal hipótesis se presenta opera el principio de prevención que se materializa en mecanismos jurídicos, tales como la evaluación del impacto ambiental o el trámite y expedición de autorizaciones previas, cuyo presupuesto es la posibilidad de conocer con antelación el daño ambiental y de obrar, de conformidad con ese conocimiento anticipado, a favor del medio ambiente (ccc, 2010c).

Ahora, la ccc en Sentencia C-632 de 2011, aunque no define lo que debe entenderse por daño ambiental, sí establece quiénes son los sujetos pasivos o 'víctimas' de este, observando el valor intrínseco del ambiente como sujeto de derechos que requiere protección autónoma. Igualmente, señala las medidas de compensación, reconociendo que no existe una enumeración taxativa, pero que estas se circunscriben a los límites de la valoración técnica del daño o impacto negativo, incluyendo el proceso de restitución y restauración ecológica, la magnitud del daño sufrido por los ecosistemas y el alcance de la medida definida, todo lo cual debe estar encaminado a establecer una restitutio in natura del daño al activo natural afectado, por medio de medidas necesarias para volver al estado anterior las cosas cuando sea posible (ccc, 2011). Concluye la ccc en la precitada sentencia que las subreglas constitucionales que deben ser tenidas en cuenta al momento de concretar las medidas compensatorias ambientales:

i) están dirigidas, única y exclusivamente, a restaurar in natura el medio ambiente afectado, buscando que éste retorne a la situación en que se encontraba antes del daño ambiental, o a lograr su recuperación sustancial; ii) las mismas se encuentran a cargo de organismos técnicos de naturaleza administrativa, y solo resultan imponibles si se demuestra la existencia de la infracción ambientaly del daño ocasionado al medio ambiente o a los recursos naturales; iii) en razón a su carácter estrictamente técnico, no están definidas previamente en la ley y su determinación depende del tipo de daño que se haya causado al medio ambiente; iv) cualquiera sea la medida compensatoria a adoptar, la misma debe guardar estricta proporcionalidad con el daño ambiental, pudiendo, en todo caso, ser objeto de los respectivos 
controles administrativo y judicial; finalmente, v) tales medidas no tienen naturaleza sancionatoria, pues el fin que persiguen es esencialmente reparatorio.

Para la ccc $(1998,2004,2010 d)$, como se puede observar en las sentencias C-320 de 1998, T-294 de 2004 y T-851 de 2010, el daño ambiental además es visto como un componente que afecta el derecho al ambiente sano, con la correspondiente incidencia en la vida de los seres vivos. En principio, refiere indistintamente a daño ecológico y ambiental, como una obligación del Estado para buscar la prevención del daño a través del manejo de los factores de deterioro y exigiendo a su vez la reparación de los daños causados conforme a lo establecido en el artículo 80 de la Constitución Política, sea o no el resultado de la realización de una actividad lícita (conducta antijurídica).

Ahora, en cuanto a la jurisprudencia desarrollada por el Consejo de Estado de Colombia (CEC), se puede identificar una aproximación conceptual del daño desde el caso Fundación Biodiversidad vs. Dagma (2000), concebido como acción proveniente de los humanos que ataca o impacta los elementos ambientales en el entendido de producir un daño social por afectación de los 'intereses difusos' y que también puede ser el producto de una defectuosa evaluación de la autoridad ambiental al evaluar los proyectos por acción u omisión (criterio reiterado en la sentencia de acción popular, caso Fundepúblico vs. IDU) (2009) (cEc, 2000, 2009).

Sin embargo, el Consejo de Estado, quien a su vez retoma la sentencia de la csj en el caso Ampeatum vs. Mesta Shipping Company y otros (2011), refiere a la definición del 'daño ambiental puro' afectación a los bienes 'naturales' y el 'ambiente' por su contenido colectivo, y 'consecutivo o impuro' cuando se trata de otros elementos afectación en la salud o patrimonio de los humanos desarrollados básicamente por la doctrina, en el cual se resalta la necesidad de 'remediar' o 'rehabilitar' el daño ambiental (causados en este caso a los cuerpos de agua), es decir que se establece una obligación para tratar de volver las cosas a su estado anterior (por ejemplo, en la sentencia de acción de grupo del Consejo de Estado, caso Hernández Santacruz y otros vs. Ministerio de Ambiente y Ecopetrol) (CEc, 2004). En fin, el daño ambiental puro son todos los perjuicios que se causan directamente al ambiente, con independencia de los derechos subjetivos de las personas que se vean afectadas (cEc, 2013). Mientras el 'daño ambiental impuro' se presenta cuando, pese a existir una afectación de 
carácter colectivo, se generan de igual manera perjuicios de índole particular, "daños individuales que son la consecuencia o el reflejo de la lesión ambiental [...] cuyo derecho no es de corte subjetivo-colectivo, sino subjetivo-individual" (Geneviève y Patrice, 1998; cEc, 2014b). ${ }^{8}$

Una concepción más amplia del daño ambiental, puede verse, por ejemplo, en la sentencia de acción popular del Consejo de Estado, caso Colina vs. Ministerio de Ambiente y otros (cEc,2007b), desde la órbita de la prevención, en la cual el daño se tiene como aquel que impide percibir los beneficios que ofrecen los bienes naturales y ambientales; en consecuencia, la reparación da derecho a reclamar la respectiva indemnización, la cual incluye, de una parte, "los costos contraídos o que se vayan a contraer por concepto de las medidas razonables de restauración del medio ambiente contaminado"y, de otra parte, los gastos incurridos en la toma de medidas preventivas, siempre y cuando haya una amenaza grave e inminente de daños por contaminación. ${ }^{9}$

Otro aspecto importante de la jurisprudencia administrativa se encuentra en el caso de la sentencia del CEC del $1^{\circ}$ de marzo de 2011, en la cual se prescribe la solución de los costos contraídos para atender las medidas restaurativas del 'medio ambiente contaminado' y los gastos por las medidas preventivas, que serían las medidas inmediatas para contrarrestar los efectos del daño ambiental, para lo cual una de las finalidades de la función administrativa radica en perseguir la compensación del daño ambiental y social, con arreglo a la ley (cEc, 2011).

Por otra parte, en relación con la teoría general del daño, el cec ha desarrollado en la sentencia del caso Buitrago Quinteros y otros vs. Distrito Capital de Bogotá (2012) cierta argumentación para interpretar el artículo 90 constitucional, en el cual se determina que "el Estado responderá patrimonialmente por los daños antijurídicos que le sean imputables, causados por la acción o la omisión de las autoridades públicas”. Desde esta perspectiva, se incluye no solamente el daño patrimonial, sino también el daño moral, y el daño fisiológico asociado por afectación a la vida de relación, que comprende

${ }^{8}$ El cec remite, e. g., al trabajo de Geneviève y Patrice (1998) respecto a la diferenciación conceptual de daño ambiental puro y daño ambiental impuro.

${ }^{9}$ Esta perspectiva del daño puede circunscribirse en una visión más utilitarista, es decir, la importancia sobre los beneficios percibidos de los servicios que ofrecen los ecosistemas, mas no por el valor intrínseco que también poseen estos. 
la afectación a salud e integridad de las personas por alteraciones a las condiciones de existencia.

\subsection{Aproximación teórica del daño ambiental}

A continuación, se presenta una perspectiva del daño desde el punto de vista teórico, que indica la superación de las posiciones que se plantean desde la responsabilidad civil y, más bien, bajo perspectivas integrales o garantistas desde la responsabilidad ambiental. Aquí es necesario comenzar con una serie de cuestiones previas a la conceptualización jurídica del daño ambiental: en primer lugar, que el daño está íntimamente ligado con las acciones o conductas desplegadas por agentes, sujetos o individuos, identificadas en la contaminación y los impactos ambientales sobre los cuales debe analizarse su grado de interacción; en segundo lugar, que la ausencia de medidas preventivas, restaurativas, restitutivas in natura y compensatorias del daño ambiental conlleva la generación de 'pasivos ambientales'; $y$, en tercer lugar, que, a pesar de observar elementos de la responsabilidad civil extracontractual en el procedimiento sancionatorio ambiental, realmente lo que se busca a la luz de la normatividad ambiental, los principios ambientales, las disposiciones constitucionales y los avances jurisprudenciales, es el reconocimiento del concepto de daño ambiental y responsabilidad ambiental, que, si bien integra elementos importantes en diferente dimensión, va más allá de los esquemas puros de responsabilidad civil.

Al respecto, diferentes teóricos han advertido que la finalidad del derecho ambiental es precisamente garantizar a través de los instrumentos jurídicos la protección del ambiente como un derecho, bien e interés de carácter colectivo, defensa que puede resultar precaria desde las perspectivas civilistas, que se encuentran naturalmente enmarcadas en una lógica distinta. Para aclarar esto, se menciona la definición jurídica de 'contaminación' establecida en la Ley 23 de 1973 y en el Decreto 2811 de 1974 (Código Nacional de Recursos Naturales Renovables, CNRNR) como "la alteración del ambiente con sustancia o formas de energía puesta en él, por actividad humana y de la naturaleza, en cantidades, concentraciones o niveles capaces de interferir el bienestar y la salud de las personas, atentar contra la flora y la fauna, degradar la calidad del ambiente de los recursos de la nación o de los particulares". Conforme a esto, se concluye que la 'contaminación' está en un nivel inferior y, por lo tanto, puede definirse como la situación fáctica o factor causante de deterioro y del daño ambiental, que, si bien no es exclusiva, se suma a otras acciones para 
conformar el conjunto de efectos o impactos ambientales negativos que dan origen a la generación del daño ambiental (Briceño, 2009).

En cuanto al daño ambiental, desde el punto de vista dogmático, se ha identificado como la afectación, disminución o aminoración sobre el valor del bien o recurso natural y ambiental, desde lo cual se produce un desconocimiento de los derechos e intereses ambientales colectivos. Según Hinestrosa (1964, p.334), “daño es la lesión del derecho ajeno consistente en el quebrantamiento económico percibido, en la manera patrimonial sufrida por la víctima, a la vez que el padecimiento moral que la acongoja”. En los desarrollos de Bustamante Alsina (1972, p. 143), daño significa "el menoscabo que se experimenta en el patrimonio por el detrimento de los valores económicos que lo componen (daño patrimonial) y también la lesión a los sentimientos, al honor o a las afecciones legítimas (daño moral)”. De acuerdo con Tamayo (1998, p. 5), el "daño civil indemnizable es el menoscabo a las facultades jurídicas que tiene una persona para disfrutar de un bien patrimonial o extrapatrimonial” (p. 5). Y, para Henao (2009, p. 195), "el daño es la lesión —incluso la minoración no necesariamente económica - de un interés lícito, por su pérdida definitiva o por la amenaza en su goce pacífico". ${ }^{10}$

Un elemento que se reitera es que el daño puede estar ocasionado tanto en actividades ilegales o antijurídicas como en actividades amparadas legalmente, con lo cual también se incluyen los casos de abuso o desconocimiento de la autorización por parte de la autoridad ambiental, como las concesiones, permisos o licencias ambientales otorgadas (Uribe Vargas y Cárdenas Castañeda, 2010). ${ }^{11}$ Sobre este punto todavía existen vacíos sobre los ordenamientos jurídicos y la jurisprudencia, es decir, sobre los daños ambientales que son autorizados legalmente, pero que son objeto de medidas de control, manejo ambiental y seguimiento por parte de las autoridades ambientales a través de las autorizaciones en los actos administrativos, con lo cual el problema de daño ambiental se remitiría a los hechos en que los titulares de la autorización desconocen las medidas allí impuestas. En consecuencia, se observa claramente que el tema del daño ambiental se enmarca dentro de las instancias de las autorizaciones

10 Siguiendo las definiciones de la dogmática del derecho, que han sido compiladas por Amaya (2002), respecto a los avances teóricos de la responsabilidad por daños al ambiente.

11 Sobre el daño ambiental transfronterizo que puede ser originado incluso en actividades amparadas legalmente. 
ambientales como la licencia ambiental, pero también correlativamente desde las medidas de carácter sancionatorio.

Conforme a todo lo anterior, se observa el deber del Estado en cabeza de los órganos que lo conforman de tomar las medidas encaminadas a prevenir o evitar la generación del daño ambiental, y, de igual manera, garantizar los mecanismos para su compensación, indemnización y reparación integral. Es necesario advertir que la generación de un daño ambiental, además, puede extenderse más allá de las fronteras nacionales, por lo cual se exige a los Estados adoptar todas las medidas de forma diligente para evitarlo, y, de lo contrario, tomar medidas para su restitución a las condiciones anteriores cuando no se trate de daños irreversibles (Uribe Vargas y Cárdenas Castañeda, 2010).

Ahora bien, cuando se identifica la falta o ausencia de medidas preventivas, restaurativas o compensatorias efectivas, se produce como consecuencia la generación de pasivos y de deudas ambientales en tanto vínculo obligacional. Entonces, dada la relación de todos estos elementos, se puede analizar la interrelación entre 'contaminación', impactos y daños ambientales, la cual se determina del alcance de cada uno de los elementos frente a las medidas preventivas y compensatorias; cuando ya no es posible evitar, corregir o mitigar el impacto ambiental negativo, se desencadena la aparición del daño ambiental (ver figura 3.1) (Ávila, 2014). ${ }^{12}$

Por su parte, las 'medidas de compensación ambiental'surgen como acciones u obligaciones contraídas u originadas en la generación de daños efectuados sobre el ambiente, aunque diferenciadas en las instancias de autorización ambiental, respecto a los impactos ambientales, y los estadios que se derivan de la potestad sancionatoria del Estado por la comisión de un daño ambiental ocasionado. En esta medida, la falta de prevención y compensación del daño ambiental implica la aparición de la deuda o del pasivo ambiental, ${ }^{13}$ entendido jurídicamente

\footnotetext{
${ }^{12} \mathrm{El}$ daño es el elemento fáctico que se define como una fuente de la responsabilidad ambiental, que genera una obligación (de prevención, mitigación, reparación integral, medidas coercitivas, sanciones, de no repetición, etc.) y comporta las características de ser actualizable y exigible jurídicamente en el tiempo, pues en cada momento manifiesta sus efectos lesivos a la sociedad, en tanto no permite acceder, intercambiar, explotar, usar, consumir o aprovechar los elementos que conforman el ambiente y los recursos naturales (Ávila, 2014).

${ }^{13}$ Los 'pasivos ambientales' son deuda actualizable y exigible, surgida del vínculo obligacional de no dañar el ambiente con ocasión del uso, aprovechamiento, extracción, intercambio, consumo o explotación del ambiente y los recursos naturales (Ávila, 2014).
} 


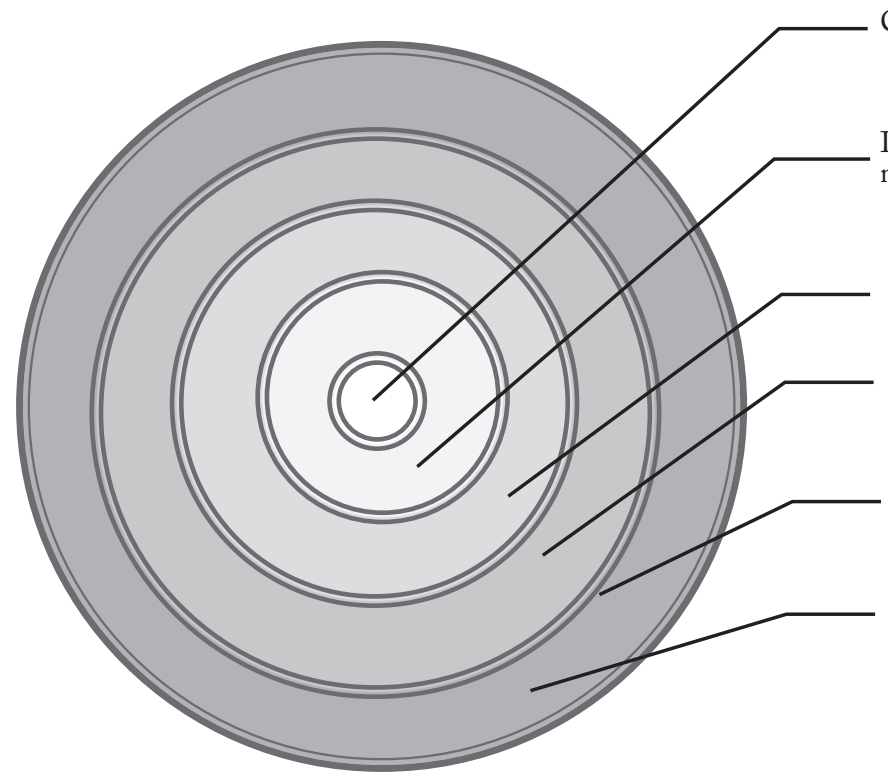

Deuda y/o responsabilidad por los impactos y/o daños ocasionados
Contaminación

Impacto ambiental negativo

\section{No prevención} o restauración

Efectos ambientales acumulados

Daño ambiental y/o impactos no evitados, corregidos, mitigados o sustituidos

Generación del pasivo ambiental

a través de

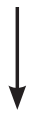

Apropiación indebida del ambiente

Figura 3.1. Esquema explicativo sobre la interrelación entre contaminación, impactos ambientales y daño ambiental (generación del pasivo ambiental)

Fuente: modificado a partir de Ávila (2014).

como el vínculo obligacional y elemento de la responsabilidad, que se refiere al acto por el cual una parte se obliga con otra a dar, hacer o no hacer alguna cosa. Dentro de la estructura de las obligaciones, se identifica la preexistencia de un sujeto activo, sujeto pasivo y un objeto (deuda o prestación), es decir que entre estos medie un vínculo jurídico creado por la ley o por un acto jurídico, en el que se imponga el deber de actuar. Entonces, se trata de un mandato por el cual una persona determinada debe realizar una prestación en provecho de otra, quien a su turno lo debe procurar (Ospina, 1987). ${ }^{14}$

${ }^{14}$ Refiere Ospina (1987) al contenido del artículo 1494 del Código Civil colombiano (crc, 1887), según el cual "las obligaciones nacen, ya del concurso real de las voluntades de dos o más personas, como en los contratos o convenciones; ya de un hecho voluntario de la persona que se obliga, como en la aceptación de una herencia o legado y en todos los cuasicontratos; ya a consecuencia de un hecho que ha inferido 
Es así como, en las fuentes de las obligaciones, el daño o menoscabo aparece como la consecuencia del incumplimiento de una obligación contractual o extracontractual o la falta de cuidado ante situaciones de riesgo, peligro o amenaza, de lo cual surge un juicio de 'responsabilidad'o reproche por la acción u omisión que dio lugar a que se materializara aquel, y que se identifica a través del 'nexo causal'. En este sentido, el daño corresponde a uno de esos elementos esenciales alrededor del cual gira todo el derecho frente a la responsabilidad, pues sin daño no se predicaría, y es, en consecuencia, presupuesto básico de la obligación de indemnizar y que se define como "todo hecho modificador de una realidad preexistente que afecta a un sujeto de derecho en su persona, su patrimonio o sus sentimientos" (Sarmiento García,2009). Sobre las categorías del daño, este se subdivide, desde el punto de vista dogmático y jurisprudencial, en: 1) el daño material o patrimonial, que a su vez se compone por (a) el daño emergente y (b) el lucro cesante; y 2) el daño inmaterial o extrapatrimonial, compuesto por (a) el daño moral,(b) el daño a la vida de relación y (c), el daño a la salud como categoría autónoma del daño inmaterial, diferenciando además entre el daño patrimonial, definido como la lesión a un interés económico, y el daño extrapatrimonial, entendido como la lesión a un interés no económico (Moisá y Misset, 2008). ${ }^{15}$

Ahora bien, en referencia a los elementos doctrinales de la responsabilidad civil que han sido desarrollados jurisprudencialmente, Mesa Cuadros (2001) aclara el alcance en referencia al daño y a la generación del 'pasivo ambiental' de la siguiente manera:i) la conducta o hecho de un sujeto (incumplimiento de la obligación o deber preexistente) que corresponde probar al peticionario o demandante; ii) un daño (perjuicio ocasionado a la víctima en razón a la conducta del sujeto), que requiere que sea cierto, directo (nexo de causalidad entre la conducta del sujeto y el daño), actual (previo a la solicitud de indemnización); excepcionalmente el daño futuro puede ser indemnizado, cuandoquiera que exista certeza de que ocurrirá; iii) nexo causal entre la conducta del sujeto y el

injuria o daño a otra persona, como en los delitos; ya por disposición de la ley, como entre los padres y los hijos de familia".

${ }^{15}$ Ahora bien, en Colombia el Consejo de Estado ha desarrollado una extensa línea jurisprudencial sobre la clasificación del daño, de la siguiente forma: 1) daño material, compuesto por (i) daño emergente y (ii) lucro cesante; y 2) daño inmaterial, en el que se incluyen (i) perjuicio moral, (ii) daños a bienes constitucionales y convencionales, (iii) daño a la salud derivado de perjuicios físicos o psicológicos y (iv) daño a la vida de relación (en razón a la relación de vida con los demás que está alterada drásticamente en sus condiciones de existencia por cambios fisiológicos, psicológicos o sociales) (CEc, 2006, 2007a, 2014a). 
daño; y iv) la culpa, como un elemento subjetivo que cualifica la conducta del agente, lo cual doctrinariamente también se define como aquel error de conducta en el cual no habría incurrido un hombre prudente y diligente (Mesa Cuadros, 2011).

Teniendo en cuenta todo lo anterior, surge un gran interrogante en relación con el daño ambiental sobre las limitantes de los conceptos y esquemas de la responsabilidad civil para afrontar el problema de los derechos e intereses colectivos involucrados. Una aproximación general indica que el esquema de responsabilidad civil se caracteriza naturalmente por una 'visión patrimonialista', resguardada en una férrea defensa del derecho de propiedad en un marco filosófico y jurídico que catapulta al individuo propietario como epicentro de la sociedad, para lo cual no resultaría suficiente para defensa de la noción de lo colectivo como corporeidad integral que representa los fines, la convivencia, el esfuerzo solidario y garantista generacional en la competencia humana (Briceño, 2009; Ávila, 2014).

En consecuencia, y siguiendo los desarrollos de Rodas Monsalve (1995), es necesario superar esa 'visión civilista' parcial, divisible y dependiente de los derechos y bienes ambientales, pues en realidad el ambiente comporta características de bien y derecho 'inmaterial, unitario y autónomo', que, por sus múltiples repercusiones, no puede reducirse a la responsabilidad entre dos sujetos que se disputan un derecho de carácter individual. En los mismos términos expresados por la evolución del derecho y la jurisprudencia comparada sobre el tema del daño ambiental, el autor advierte la necesidad de encontrar una nueva dirección de la responsabilidad fundada en una teoría objetiva bajo la premisa del papel del actor principal constituido por las 'víctimas', para lo cual resulta más adecuado concebir una teoría basada en los riesgos, amenazas y peligros que genera el contaminador con sus acciones u omisiones para la vida de los seres humanos y no humanos, y las afectaciones sociales y ecológicas, a fin de evitar los impactos negativos que se producen a manera de 'daños anónimos' difíciles de tratar en el esquema de responsabilidad actual. Del mismo modo, Mesa Cuadros (2011) y Ávila (2014) señalan la conveniencia de arribar a esquemas de responsabilidad objetiva en materia ambiental, en la cual baste únicamente con probar los efectos causados por el hecho dañino (por ejemplo, en la persistencia en el tiempo en que se presentan los efectos o en que aparecen y en la magnitud de la afectación, lo que desdibuja los esquemas de responsabilidad en cuanto resulta difícil individualizar al responsable). 
A pesar de la necesidad de este cambio, la Ley 1333 de 2009 (CRC), claramente ha optado por desarrollar la responsabilidad civil clásica, que se subdivide en contractual o extracontractual, teniendo esta última como la fuente de la gran mayoría de los daños perpetrados al ambiente, donde se aplica la fórmula tradicional que involucra, según lo establecido en el artículo 2341 del Código Civil, la demostración de la 'culpa aquiliana' (lo que debió hacer y no se hizo), acción dañosa, el daño y relación de causalidad entre aquella y este. Otro elemento importante en la teoría del daño ambiental se remite a los deberes de prevención, compensación o restitución y resarcimiento e indemnización que deben ser vistos a la luz de la Ley 1333 de 2009 (CRC). En este sentido, la responsabilidad implica la obligación de reparar el daño tratando de volver al estado anterior de las cosas cuando sea posible, para lo cual debe tomar medidas para 'restituir', 'compensar'y 'satisfacer' el ambiente afectado.

Teniendo en cuenta las discusiones anteriores, claramente la visión civilista-privatista está más enfocada en la indemnización económica monetaria o patrimonial del daño ambiental (que se puede considerar como un elemento adicional, pero no el único) que en la prevención de este, debido a que no repara en las medidas ex ante de prevención, mitigación o corrección, sino que se inclina por externalizar las cargas ambientales al resto de la sociedad, asumiendo de manera reducida ex post parte de los daños ocasionados con posibles indemnizaciones de carácter monetario (Daly y Cobb, 1997; Laffont, 2008). ${ }^{16}$ Aquí se vislumbra notoriamente uno de los mayores problemas en materia ambiental, el de la valoración ambiental económica, que responde a elementos mucho más complejos que la visión patrimonialista del esquema de responsabilidad civil (Ávila, 2014), es decir que, si bien se hace necesario integrar los valores monetarios, no son los únicos en perspectiva de una valoración y restablecimiento integral de los derechos transgredidos.

Analizando detenidamente el procedimiento sancionatorio ambiental, se diferencian tres dimensiones: 1) la 'sanción' como una consecuencia jurídica que busca el cambio de la conducta encaminada a modificar las actuaciones del responsable por haber infringido el ordenamiento jurídico y que puede

\footnotetext{
${ }^{16}$ Según Daly y Cobb (1997) y Laffont (2009), desde la economía, las 'externalidades'se definen como el comportamiento de un agente que afecta al bienestar de un tercero (de manera positiva o negativa), sin que este último haya elegido esa modificación, y sin que exista un precio o valor de la contraparte que lo compense. Un término asociado es el de 'des-economía'. Referido a las externalidades negativas, son aquellas que disminuyen el nivel de bienestar.
} 
contener diferentes obligaciones, incluyendo las de carácter pecuniario, por ejemplo, las multas a favor del Estado como castigo por haber incurrido en un acto indebido; diferente de 2) las medidas restaurativas y compensatorias que considere la autoridad ambiental dentro del procedimiento sancionatorio; distinto también de 3) la responsabilidad indemnizatoria y resarcitoria frente a los daños ocasionados a terceros en materia civil (daño ambiental impuro), en la cual se deberá incluir la compensación consistente en el pago por daños financieramente evaluables, debiendo incluir las pérdidas de los beneficios en el grado en que sean establecidos. Lo anterior ha sido aclarado precisamente por la jurisprudencia constitucional, de acuerdo con lo cual "las sanciones y las medidas preventivas en materia ambiental tienen finalidades de prevención, correctivas y compensatorias, pero no resarcitorias o indemnizatorias. De ahí que el fundamento jurídico de la responsabilidad civil es diferente a la administrativa ambiental, no siendo posible equiparar el modelo de culpabilidad exigida" (ccc, 2010b).

En este sentido, claramente se indica que no es posible asimilar la responsabilidad ambiental con la responsabilidad civil, más cuando esta última está diseñada ontológicamente bajo un enfoque individual o contractual que dista de la conceptualización de bien común o un derecho e interés colectivo desde una visión patrimonialista pura (ver tabla 3.1) (Briceño, 2009).

Tabla 3.1. Comparación entre teorías de responsabilidad civil y ambiental para el tratamiento de pasivos ambientales

\begin{tabular}{|l|l|}
\hline \multicolumn{1}{|c|}{ Responsabilidad civil privatista } & \multicolumn{1}{c|}{ Responsabilidad ambiental } \\
\hline $\begin{array}{l}\text { Reconocimiento de responsabilidad mínima del } \\
\text { daño ambiental o incapacidad de reconocimiento } \\
\text { del daño. }\end{array}$ & $\begin{array}{l}\text { Responsabilidad ampliada, compartida, pero di- } \\
\text { ferenciada frente a la contaminación, los pasivos } \\
\text { ambientales y las deudas ambientales. }\end{array}$ \\
\hline $\begin{array}{l}\text { Tendencia al desconocimiento sobre el pasivo } \\
\text { ambiental ocasionado por modelo privado de } \\
\text { rentabilidad mediante generación de externali- } \\
\text { dades negativas. }\end{array}$ & $\begin{array}{l}\text { Reconocimiento del pasivo ambiental acumulable } \\
\text { (responsabilidad histórica) por el uso, aprovecha- } \\
\text { miento, explotación, consumo, apropiación e inter- } \\
\text { cambio indebido e injustificado sobre el ambiente. }\end{array}$ \\
\hline $\begin{array}{l}\text { Desconocimiento de los derechos intergeneracio-- } \\
\text { nales por la visión a corto plazo. }\end{array}$ & $\begin{array}{l}\text { Visión a largo plazo y reconocimiento de los dere- } \\
\text { chos intergeneracionales a través de la prevención } \\
\text { de los pasivos ambientales. }\end{array}$ \\
\hline $\begin{array}{l}\text { Visión compensatoria mínima sustentada de ma- } \\
\text { nera exclusiva en valores monetarios. }\end{array}$ & $\begin{array}{l}\text { Reparación integral sustentada en la pluralidad de } \\
\text { valores adicionales a los valores monetarios sobre } \\
\text { las víctimas y medidas adicionales de carácter } \\
\text { resarcitorio. }\end{array}$ \\
\hline
\end{tabular}




\begin{tabular}{|l|l|}
\hline $\begin{array}{l}\text { Aplicación de justicia procedimental mínima se- } \\
\text { gún acuerdo entre las partes en el proceso. }\end{array}$ & $\begin{array}{l}\text { Posición garantista procedimental frente a los } \\
\text { derechos ambientales colectivos. }\end{array}$ \\
\hline $\begin{array}{l}\text { Teoría de responsabilidad subjetiva a través de la } \\
\text { comprobación del daño, el hecho y un nexo causal } \\
\text { entre los dos elementos anteriores. }\end{array}$ & $\begin{array}{l}\text { Necesidad de aplicación de responsabilidad obje- } \\
\text { tiva, sin vincular el factor culpabilidad, a través de } \\
\text { la presunción entre el hecho generador y el daño } \\
\text { ocasionado. }\end{array}$ \\
\hline $\begin{array}{l}\text { Perspectiva de incremento de la deuda ambiental } \\
\text { por rentabilidad inmediata o exigencia del 'pago' } \\
\text { de las deudas ambientales. }\end{array}$ & $\begin{array}{l}\text { Demanda de la irrupción o terminación de la } \\
\text { deuda ecológica y ambiental a través de la rei- } \\
\text { vindicación de la justicia ambiental redistributiva } \\
\text { entre sectores de la sociedad. }\end{array}$ \\
\hline
\end{tabular}

Fuente: tomado de Ávila (2014).

Por lo tanto, dichas medidas restaurativas y compensatorias pueden estar referidas a disposiciones para integrar el restablecimiento frente al daño ecológico y social, incluyendo medidas diversas para la descontaminación de los ecosistemas e, incluso, el arrepentimiento público expresado por la comisión del daño, a fin de recuperar la confianza legítima que ha sido quebrantada de la sociedad frente al Estado. Todas estas medidas se encaminan a la misma dirección de las observaciones sobre los problemas de valoración ambiental, reconociendo que el ambiente excede la visión de sustitución entre valores en términos económicos y monetarios del capital natural y el capital hecho por humanos (man-made capital), por la imposibilidad de no poder traducir todo en unidades de dinero o de renta de capital, por lo cual se indica la preocupación esencial con miras a garantizar la conservación, la sostenibilidad y los valores intrínsecos e inmanentes del ambiente y la naturaleza para las presentes y futuras generaciones (Martínez Alier, 1995, 2002). ${ }^{17}$ Todo esto también llama a la reflexión de los diferentes actores en la necesidad o conveniencia de esencialmente prevenir el daño ambiental como valor supremo bajo esquemas de responsabilidad ambiental por observar en las actividades históricas de uso, aprovechamiento, explotación, extracción, consumo e intercambio del ambiente y los recursos naturales.

\section{Conclusiones}

De acuerdo con la jurisprudencia y los desarrollos teóricos, el daño ambiental es fuente de responsabilidad y está definido jurídicamente como la afecta-

${ }^{17}$ En ambos trabajos, Martínez Alier (1995) hace referencia a la 'sustituibilidad' entre capital natural y capital artificial (man-made capital), así como al proceso de 'monetización de la naturaleza'. 
ción, disminución o aminoración sobre el valor del bien o recurso natural y ambiental, que conduce al desconocimiento de los derechos e intereses ambientales colectivos, generado tanto en actividades ilegales o antijurídicas como en actividades amparadas legalmente, que, a pesar de estar precedidas de una autorización otorgada por la autoridad ambiental (e.g., concesiones, permisos o licencias ambientales), implican casos de abuso o desconocimiento por parte de su titular.

En el ordenamiento jurídico interno y en el DAI, se observan dos tipos de medidas frente al daño ambiental: la primera es el deber del Estado de cara a la planificación del manejo y aprovechamiento de los recursos naturales, a fin de garantizar su desarrollo sostenible, su conservación, restauración o sustitución, para lo cual se le exige prevenir y controlar los factores de deterioro ambiental, imponer las sanciones legales y exigir la reparación de los daños causados, respondiendo además por los daños ambientales antijurídicos ocasionados en el ejercicio de sus actividades; y la segunda, la responsabilidad de los particulares frente al daño ambiental y el uso inadecuado de los elementos ambientales. Del mismo modo, se exige al Estado asumir su responsabilidad internacional por daños transfronterizos ocasionados a otros países. Y garantizar a nivel interno los procedimientos administrativos y judiciales encaminados a reparar el daño, así como desarrollar la legislación nacional relativa a la responsabilidad y la indemnización respecto de las víctimas de la contaminación y otros daños ambientales.

Dentro de la jurisprudencia comparada, se han identificado notables progresos de la conceptualización del daño ambiental que van más allá de las fases de la responsabilidad civil, que, si bien aporta elementos importantes, se considera insuficiente para abordar el tema desde una perspectiva de valoración, restablecimiento o reparación integral del daño más allá de una visión patrimonialista y/o monetaria. Por otra parte, se requiere que se configuren posiciones cada vez más inclusivas y garantistas con planteamientos sobre las problemáticas ambientales que incluyan una perspectiva ecológica asociada a los bienes afectados, integrando a su vez aspectos sociales y elementos efectivos de protección, lo que, en otras palabras, implica una visión integral de los problemas de valoración ambiental del daño. En la jurisprudencia internacional, se han incluido elementos sociales que sobrepasan la apreciación del simple daño ecológico en las medidas de compensación relacionadas con valores y principios sociales fragmentados 
(por ejemplo, la 'confianza legítima' de la sociedad y las comunidades frente a las medidas del Estado).

En la jurisprudencia nacional, también se han visto avances en el mismo sentido, que van desde la diferenciación entre el 'daño ambiental puro', definido como todos los perjuicios que se causan directamente al ambiente, con independencia de los derechos subjetivos de las personas que se vean afectadas, y el 'daño ambiental impuro', entendido como aquel que, pese a existir una afectación de carácter colectivo, recae de manera exclusiva sobre perjuicios de índole particular, "daños individuales que son la consecuencia o el reflejo de la lesión ambiental [...] cuyo derecho no es de corte subjetivo-colectivo, sino subjetivo-individual". En la jurisprudencia constitucional, se relaciona el daño ambiental tanto al instrumento de manejo y control para prevenir, mitigar y corregir sus efectos, como al procedimiento sancionatorio ambiental. En este último, se aclara la función sancionatoria y medidas preventivas del artículo 4º de la Ley 1333 de 2009 y la diferencia entre la sanción (artículo 40 ibíd.) y el cumplimiento de las medidas de compensación y restauración del 'daño' o el 'impacto' cuando la autoridad ambiental competente estime necesario (artículo 31 ibíd.), frente a lo cual concluye que "las sanciones y las medidas preventivas en materia ambiental tienen finalidades de prevención, correctivas y compensatorias, pero no resarcitorias o indemnizatorias". Además, se hace énfasis desde la interpretación constitucional en las medidas de prevención, las cuales están ligadas a los principios ambientales de precaución y prevención, que además tienen gran connotación frente a los daños graves e irreversibles sobre el ambiente. $Y$ en cuanto a las medidas de compensación, la jurisprudencia constitucional manifiesta el deber de establecer una restitutio in natura del daño al activo natural afectado, por medio de medidas necesarias para volver al estado anterior las cosas cuando sea posible.

Desde el punto de vista teórico, se diferencia entre la contaminación y los demás impactos ambientales como acciones y situaciones fácticas que originan el daño ambiental. Se afirma además que la falta de prevención y compensación del daño ambiental conlleva la aparición de la deuda y del pasivo ambiental, entendido jurídicamente como el vínculo obligacional y elemento de la responsabilidad, en el que se refiere al acto por el cual una parte se obliga con otra a dar, hacer o no hacer alguna cosa, para el caso vinculadas al ejercicio 
de actividades inadecuadas ${ }^{18}$ por el uso, aprovechamiento, explotación, extracción, consumo e intercambio cuidadoso del ambiente y los recursos naturales.

Finalmente, se podría decir que los desarrollos anotados indican una tendencia hacia la superación de la 'visión patrimonialista' parcial, divisible y dependiente de los derechos y bienes ambientales de la perspectiva civilista, enfocada naturalmente a la indemnización económica monetaria o patrimonial de cierta parte del daño ambiental, más que en la prevención de este, auspiciada en ciertos eventos por la lógica de externalizar los costos ambientales al resto de la sociedad. Frente a esto, como bien lo ha establecido el ordenamiento jurídico, la jurisprudencia y el desarrollo dogmático, se observa la inconveniencia de asimilar la responsabilidad ambiental con la responsabilidad civil, definiendo la primera como una perspectiva de responsabilidad ampliada y diferenciada, con reconocimiento acumulable del pasivo ambiental, desde una visión a largo plazo, que demanda la reparación integral sustentada en la pluralidad de valores adicionales a los patrimoniales y/o monetarios, reconociendo el derecho de las víctimas y carácter resarcitorio con garantía plena de los derechos ambientales colectivos y que bien pueden operar como desincentivos que conduzcan a frenar los daños y pasivos ambientales.

La apuesta, bajo un visión integrativa de la sociedad, la institucionalidad, la empresa, los expertos y la academia, en un momento en que se perciben las afectaciones ambientales, radica en esencialmente prevenir o evitar impactos, daños y pasivos ambientales, articulando el desarrollo de las actividades económicas y el derecho al desarrollo de los pueblos, con el uso cuidadoso del ambiente y el aprovechamiento de los recursos naturales renovables, donde no haya perdedores, en tanto todos en su conjunto seamos ganadores.

\section{Bibliografía}

Amaya, O. (2002). Responsabilidad por daños al medio ambiente en Colombia. Memorias viri Congreso Venezolano de Derecho Ambiental: Mecanismos y Medidas Jurídicas en Defensa del Ambiente, Camino a la Cumbre sobre Desarrollo Sostenible, Universidad Metropolitana, Caracas.

\footnotetext{
${ }^{18}$ Por ejemplo, no observar los estándares o recomendaciones nacionales e internacionales o la elaboración y evaluación defectuosa de los estudios ambientales como un ejercicio eminentemente predictivo de los impactos y daños ambientales.
} 
Asamblea Nacional Constituyente de Colombia (ANC). (1991). Constitución Politica de Colombia. Bogotá, D.C.: ANc.

Ávila, T. S. (2014). Principios, derechos y pasivos ambientales: un estudio de caso sobre contaminación por residuos peligrosos en Bogotá D.C. (Colombia) (Tesis de maestría, Universidad Nacional de Colombia, Bogotá, D.C., Colombia).

Briceño, A. M. (2009). Aproximación a los conceptos de daño ecológico y de daño ambiental. En A. M. Briceño et al. (Comps.), Daño ambiental II (pp. 15-74). Bogotá, D.C.: Universidad Externado de Colombia.

Bustamante Alsina,J.(1972). Teoría general de la responsabilidad civil (4a ed., 1983). Buenos Aires: Abeledo Perrot.

Consejo de Estado de Colombia (CEc). (2000). Sentencia acción popular caso Fundación Biodiversidad vs. Dagma [Rad. Exp. Ap-031 (abril 13 de 2000)]. Bogotá, D.C.: cEc.

Consejo de Estado de Colombia (CEc). (2004). Sentencia acción de grupo caso Hernández Santacruz vs. Ministerio de Ambiente y Ecopetrol [Rad. Exp. AG 52001-23-31-000-2002-00226-01 (mayo 13 de 2004)]. Bogotá, D.C.: CEC.

Consejo de Estado de Colombia (CEc). (2006). Sentencia acción de reparación directa del 4 de diciembre de 2006 [caso Giraldo Chaves vs. Ministerio de Transporte et al., Rad. Exp. ARD 52001-23-31-000-1996-0763301(15351)]. Bogotá, D.C.: CEC.

Consejo de Estado de Colombia (cec). (2007a). Sentencia acción de grupo del 15 de agosto de 2007 [caso Ordóñez Sandoval et al. vs. Ministerio de Defensa et al., Rad. Exp. Ag. $190012331000200300385-01]$. Bogotá, D.c.: CEC.

Consejo de Estado de Colombia (CEc).(2007b). Sentencia acción popular del 22 de febrero de 2007 [caso Colina vs. Ministerio de Ambiente et al., Rad. Exp. AP. 52001-23-31-000-2004-00092-01]. Bogotá, D.C.: cec.

Consejo de Estado de Colombia (CEC). (2009). Sentencia acción popular del 4 de junio de 2009 [caso Fundación para la Defensa del Interés Público vs. Instituto de Desarrollo Urbano de Bogotá, Rad. Exp. 25000-23-25-0002002-00093-01(AP)]. Bogotá, D.C.: CEC.

Consejo de Estado de Colombia (cEc). (2011). Sentencia del $1^{\circ}$ de marzo de 2011 [acción de nulidad contra los artículos $1^{\circ}, 2^{\circ}$ y $3^{\circ}$ del Decreto 1631 de 2006]. Bogotá, D.C.: cEC. 
Consejo de Estado de Colombia (CEc).(2012). Sentencia del 1º de noviembre de 2012 [caso Buitrago Quinteros y otros vs. Distrito Capital de Bogotá, Rad. Exps. 25000232600019990002 04 y 2000-00003-04]. Bogotá, D.c.: cEC. Consejo de Estado de Colombia (cEc). (2013). Sentencia acción popular del 26 de noviembre de 2013 [caso Maldonado y otros vs. FIIC]. Bogotá, D.c.: cEC. Consejo de Estado de Colombia (CEc). (2014a). Documento ordenado con el fin de recopilar la línea jurisprudencial y establecer los criterios unificados para la reparación de los perjuicios inmateriales [Acta del 28 de agosto de 2014]. Bogotá, D.C.: CEC.

Consejo de Estado de Colombia (CEc). (2014b). Sentencia acción de reparación directa del 20 de febrero de 2014 [caso Medina vs. Ministerio de Defensa y otros, Rad. Exp. 41-001-23-31-000-2000-02956-01 (29028)]. Bogotá, D.C.: CEC.

Corte Constitucional de Colombia (ccc). (1998). Sentencia C-320 de 1998: revisión de constitucionalidad por objeciones presidenciales al proyecto de Ley 235 de 1996 Senado y 154 de 1996 Cámara, "por el cual se establece el seguro ecológico, se modifica el Código Penal y se dictan otras disposiciones". Bogotá, D.C.: ccc.

Corte Constitucional de Colombia (ccc). (1999). Sentencia C-035 de 1999 [demanda pública de inconstitucionalidad contra Ley 99 de 1993, artículo 56]. Bogotá, D.c.: ccc.

Corte Constitucional de Colombia (ccc). (2004). Sentencia T-294 de 2004: acción de tutela de Rafael Vergara Navarro contra el Juzgado $6^{\circ}$ Civil del Circuito de Cartagena y la Sala Civil del Tribunal Superior de Cartagena. Bogotá, D.C.: cCc.

Corte Constitucional de Colombia (ccc). (2010a). Sentencia C-401 de 2010: demanda de inconstitucionalidad contra el artículo 10 de la Ley 1333 de 2009. Bogotá, D.c.: ccc.

Corte Constitucional de Colombia (ccc). (2010b). Sentencia C-595 de 2010: demanda de inconstitucionalidad contra el parágrafo del artículo $1^{\circ}$ y el parágrafo $1^{\circ}$ del artículo 5 de la Ley 1333 de 2009, "por la cual se establece el procedimiento sancionatorio ambiental y se dictan otras disposiciones". Bogotá, D.c.: ccc.

Corte Constitucional de Colombia (ccc). (2010c). Sentencia C-703 de 2010: demanda de inconstitucionalidad parcial contra la Ley 1333 de 2009. Bogotá, D.c.: CCC. 
Corte Constitucional de Colombia (ccc). (2010d). Sentencia T-851 de 2010 [caso Benítez Coy vs. Alcaldía Municipal de Barbosa]. Bogotá, D.c.: ccc. Corte Constitucional de Colombia (ccc).(2011). Sentencia C-632 de 2011: demanda de inconstitucionalidad contra los artículos 31 y 40 (parcial) de la Ley 1333 de 2009, "por la cual se establece el procedimiento sancionatorio ambiental y se dictan otras disposiciones”. Bogotá, D.C.: cCC.

Corte Constitucional de Colombia (ccc). (2012a). Sentencia C-746 de 2012 [demanda de inconstitucionalidad contra el numeral 9 del artículo 52 de la Ley 99 de 1993]. Bogotá, D.c.: ccc.

Corte Constitucional de Colombia (ccc). (2012b). Sentencia T-693 de 2012 [caso Unión Temporal Desarrollo Vial del Valle del Cauca y Cauca vs. Ministerio de Ambiente y Desarrollo Sostenible]. Bogotá, D.c.: ccc.

Corte Europea de Derechos Humanos (CEDH). (1993). Sentencia del 25 de noviembre de 1993 [caso Zander vs. Suecia, No 45/1992/390/468]. Estrasburgo: CEDH (versión original en inglés).

Corte Europea de Derechos Humanos (CEDH).(1994). Sentencia del 9 de diciembre de 1994 [caso López Ostra vs. España, No 16798/90]. Estrasburgo: CEDH (versión original en inglés).

Corte Europea de Derechos Humanos (cedH). (2004). Sentencia del 10 de noviembre 2004 [caso Taskin y otros contra Turquía, No 46117/99]. Estrasburgo: CEDH (versión original en inglés).

Corte Europea de Derechos Humanos (CEDH). (2005a). Sentencia del 9 de junio de 2005 [caso Fadeyeva vs. Rusia, No 55723/00]. Estrasburgo: CEDH (versión original en inglés).

Corte Europea de Derechos Humanos (CEDH). (2005b). Sentencia del 12 de julio de 2005 [caso Okyay y otros vs. Turquía]. Estrasburgo: CEDH (versión original en inglés).

Corte Europea de Derechos Humanos (CEDH). (2006). Sentencia del 2 de noviembre de 2006 [caso Giacomelli vs. Italia, No 59909/00]. Estrasburgo: CEDH (versión original en inglés).

Corte Internacional de Justicia (cIJ). (1996). Advisory opinion of 8 July 1996: the legality of the Threat or Use of Nuclear Weapons. La Haya: cIJ.

Corte Internacional de Justicia (cIJ). (1997). Judgment of 25 September of 1997: case concerning the Gabcikovo-Nagymaros project: Hungary-Slovakia. Reports of judgements, advisory opinions and orders. 692. La Haya: CIJ. 
Corte Nacional del Ecuador (CNE). (2013). Sentencia de casación civil del 12 de noviembre de 2013 [caso Salazar y otros vs. Chevron Corp., Juicio No 174-2012]. Quito: CNE.

Corte Provincial de Sucumbíos (CPS). (2012). Sentencia del 3 de enero de 2012 [caso Salazar y otros vs. Chevron Corp.]. Nueva Loja: cPs.

Corte Suprema de Justicia de Colombia (csJ). (1976). Sentencia de casación civil instaurado por Hilanderías Medellín S.A. vs. Compañía de Productos Químicos Nacionales-Sulfácidos S.A. [Gaceta Judicial 2393, 1976: 128, 129, 130, 131 (abril 30 de 1976)]. Bogotá, D.c.: csJ.

Corte Suprema de Justicia de Colombia (csJ). (1999). Sentencia de casación civil del 25 de octubre de 1999 [caso Acosta vs. Gases del Caribe S.A.]. Bogotá, D.C.: cSJ.

Corte Suprema de Justicia de Colombia (csj). (2011). Sentencia de casación civil del 16 de mayo de 2011 [caso Ampeatum vs. Mesta Shipping Company y otros, Rad. Exp. 52835-3103-001-2000-00005-01]. Bogotá, D.c.: csJ.

Daly, H. E., \& Cobb, J. B. Jr. (1997). Para el bien común: reorientando la economía hacia la comunidad, el ambiente y el futuro sostenible. Bogotá: Fondo de Cultura Económica.

Geneviève, V., \& Patrice, J. (1998). Traité de droit civil: Les conditions de la responsabilité. Paris: LGDJ.

Gómez-Robledo, A. (1992). Responsabilidad internacional por daños transfronterizos. México, D.F.: Universidad Nacional Autónoma de México (UnAm).

Henao, J. C. (2009). De la importancia de concebir la amenaza y el riesgo sobre derechos ambientales como daño cierto. En A. M. Briceño et al. (Comps.) Daño ambiental II. Bogotá, D.C.: Universidad Externado de Colombia.

Hinestrosa, F. (1964). Derecho civil: obligaciones. Bogotá, D.C.: Universidad Externado de Colombia.

Laffont, J. J. (2008). Externalities. En S. N. Durlauf \& L. E. Blume (Eds.), The new palgrave dictionary of economy. Recuperado de http://www.dictionaryofeconomics.com

Martínez Alier,J. (1995). Curso básico de economía ecológica. México, D.F.: PNumA.

Martínez Alier, J. (2002). The environmentalism of the poor: a study of ecological conflicts and valuation. Radstock: EE Publishing.

Mesa Cuadros, G. (2011). Análisis constitucional y legal para la gestión de pasivos ambientales en el sector de hidrocarburos. En G. Mesa Cuadros (Ed.), 
Elementos para una teoría de la justicia ambiental y el estado ambiental de derecho (pp. 233-250). Bogotá, D.C.: Universidad Nacional de Colombia. Moisá, B., \& Misset, L. (2008). Daño extrapatrimonial (o moral) a las personas jurídicas. Revista Jurídica del Perú, 87, 303-363.

Rodas Monsalve, J. C. (1995). Fundamentos constitucionales del derecho ambiental colombiano (4a reimp., 1999). Bogotá, D.C.: Universidad de los Andes, Tercer Mundo.

Sarmiento García, M. G. (2009). Estudios de responsabilidad civil(2ª ed.). Bogotá, D.C.: Universidad Externado de Colombia.

Tamayo,J. (1998). De la responsabilidad civil.IV. De los perjuicios y su indemnización (2a ed., 1999). Bogotá, D.C.: Temis.

Trail Smelter Arbitral Tribunal (тSAT). Laudo arbitral caso Estados Unidos vs. Canadá, Trail Smelter Case (11 de marzo de 1941) (ed. en inglés, 2006).

Uribe Vargas, D., \& Cárdenas Castañeda, F. A. (2010). Derecho internacional ambiental. Bogotá, D.C.: Fundación Universitaria Jorge Tadeo Lozano. 